\title{
Acceptability of Lettuce Treated with a Lactic Acid and Hydrogen Peroxide Antibacterial Solution
}

\author{
K. H. McWatters
}

I. B. Hashim

S. L. Walker

M. P. Doyle

A. P. Rimal

Missouri State University

Follow this and additional works at: https://bearworks. missouristate.edu/articles-coa

\section{Recommended Citation}

McWatters, K. H., I. B. Hashim, S. L. Walker, M. P. Doyle, and A. P. Rimal. "Acceptability of lettuce treated with a lactic acid and hydrogen peroxide antibacterial solution." Journal of food quality 25, no. 3 (2002): 223-242.

This article or document was made available through BearWorks, the institutional repository of Missouri State University. The work contained in it may be protected by copyright and require permission of the copyright holder for reuse or redistribution.

For more information, please contact BearWorks@library.missouristate.edu. 


\title{
ACCEPTABILITY OF LETTUCE TREATED WITH A LACTIC ACID AND HYDROGEN PEROXIDE ANTIBACTERIAL SOLUTION
}

\author{
K.H. McWATTERS ${ }^{1,5}$, I.B. HASHIM ${ }^{4}$, S.L. WALKER ${ }^{1}$, M.P. DOYLE ${ }^{2}$ \\ and A.P. RIMAL ${ }^{3}$ \\ Department of Food Science and Technology \\ Center for Food Safety \\ University of Georgia \\ Griffin, GA 30223-1797
}

Accepted for Publication May 10, 2001

\begin{abstract}
Whole iceberg lettuce heads were treated with $1.5 \%$ lactic acid plus $2.0 \%$ hydrogen peroxide solution (antibacterial solution) at $22 \mathrm{C}$ for $5 \mathrm{~min}$. They were then either rinsed by immersing in running tap water for 5 min or neutralized with $2.5 \%$ sodium bicarbonate solution at $22 \mathrm{C}$ for 5 min followed by rinsing (immersion in running tap water) for $10 \mathrm{~min}$, draining, and storing in sealed plastic containers at $5 C$ for 0,6 , and 10 days along with untreated controls. The antibacterial treatment resulted in marginally acceptable lettuce at day 0 ; neutralization resulted in acceptable lettuce at day 0 but unacceptable after 6 and 10 days. Consumers indicated willingness to purchase an antibacterial solution to treat lettuce at home as well as lettuce pretreated at the packinghouse/processing plant; they were willing to pay at least 3 to 5 cents more per head for pretreated lettuce. Antibacterial treatment plus neutralization provided acceptable lettuce if used in less than 6 days.

'Department of Food Science and Technology, University of Georgia, Griffin, GA 30223-1797.

2 Center for Food Safety, University of Georgia, Griffin, GA 30223-1797

${ }^{3}$ Department of Agricultural and Applied Economics, University of Georgia, Griffin, GA 30223. Present address: Southeast Missouri State University, 206 Karls Building, 901 S. National Ave., Springfield, MO 65804

${ }^{4}$ Present address: Department of Food Science and Nutrition, United Arab Emirates University, P.O. Box 17555, Al Ain, U.A.E.

5 Correspondent author. TEL: (770) 412-4737; FAX: (770) 412-4748; E-mail: kmcwatt@griffin.peachnet.edu
\end{abstract}

Journal of Food Quality 25 (2002) 223-242. All Rights Reserved.

${ }^{\oplus}$ Copyright 2002 by Food \& Nutrition Press, Inc., Trumbull, Connecticut. 


\section{INTRODUCTION}

Lettuce may become contaminated by pathogens from soil and irrigation water (Davis et al. 1988) or during preparation and packaging. In a survey of fresh vegetables from shops in Italy, $68 \%$ of lettuce was contaminated with Salmonella spp. (Ercolani 1976). Mason et al. (1976) reported that $46 \%$ of the participants at a medical conference who ate salad containing raw vegetables were infected with enteropathogenic Escherichia coli. Outbreaks of shigella (Frost et al. 1995; Kapperud et al. 1995), E. coli 0157:H7 (Ackers et al. 1996; Davis et al. 1998; Mermin et al. 1996), Cyclospora (Centers for Disease Control and Prevention 1997) and hepatitis A (Rosenblum et al. 1990) infection have been associated with lettuce. Abdul-Raouf et al. (1993) determined that $E$. coli $\mathrm{O} 157: \mathrm{H} 7$ was able to grow in shredded lettuce at 12 and $21 \mathrm{C}$.

Microbial decay of shredded lettuce is mainly due to the growth of microorganisms acquired in the field (Boyette et al. 1993). Water containing 50 to $200 \mathrm{ppm}$ of chlorine is widely used to sanitize whole fruits and vegetables as well as fresh-cut produce on a commercial scale (Beuchat et al. 1998). The International Fresh-cut Produce Association guidelines (IFPA 1996) indicate that free chlorine's germicidal rate decreases at higher water temperatures (i.e., 37C) because chlorine vaporizes; maximum chlorine solubility is achieved in water at about $3 \mathrm{C}$, therefore, cooler water is better. Chlorine concentration and water temperature vary from processor to processor, depending on the microbiological analysis of the process water, cut products, and microbiological audit of the processing line.

Washing shredded lettuce with cold, chlorinated water has limited antibacterial effect, whereas washing lettuce for $3 \mathrm{~min}$ in $47 \mathrm{C}$ water containing $100 \mu \mathrm{g} / \mathrm{mL}^{-1}$ total chlorine delayed growth of the spoilage microflora by several days (Delaquis et al. 1999). Beuchat et al. (1998) investigated spray application of chlorine (200 to $2,000 \mathrm{ppm}$ ) to raw produce, with a concentration of 2,000 $\mathrm{ppm}$ being more effective than $200 \mathrm{ppm}$. Their findings indicated that spray application of chlorine at foodservice or household levels might be a suitable and more convenient alternative to treatment than dipping or submersion. Sapers and Simmons (1998) reported that hydrogen peroxide may be an effective antimicrobial alternative to chlorine.

Preliminary trials in our laboratory revealed that treating apples and oranges with $1.5 \%$ lactic acid plus $1.5 \%$ hydrogen peroxide at $40 \mathrm{C}$ for $15 \mathrm{~min}$ was an effective antimicrobial treatment and did not affect the external quality characteristics of the fruit. However, this treatment adversely affected whole head lettuce quality by causing browning, spine damage, wilting, and loss of turgor. Further trials revealed that treating whole head lettuce at a lower temperature $(22 \mathrm{C})$ with $1.5 \%$ lactic acid plus a higher concentration of hydrogen peroxide $(2 \%)$ for shorter time $(5 \mathrm{~min})$ resulted in a more desirable product 
(appearance, color) than the initial treatment and was also effective in inactivating Escherichia coli 0157:H7, Salmonella enteritidis, and Listeria monocytogenes. However, the innermost leaves had an undesirable sour, acidic taste. Therefore, the need for a neutralization step to eliminate the sour taste became apparent. However, neutralizing the lettuce treated with the antibacterial solution using sodium bicarbonate could also affect lettuce quality. The objectives of this study were (1) to evaluate the effects of a pathogen inactivation treatment of $1.5 \%$ lactic acid plus $2 \%$ hydrogen peroxide at $22 \mathrm{C}$ for $5 \mathrm{~min}$ on the sensory quality and acceptability of iceberg lettuce (Experiment 1), (2) to evaluate the effect of a neutralization procedure on the sensory quality and acceptability of iceberg lettuce treated with the antibacterial solution (Experiment 2), and (3) to obtain information about lettuce purchasing, handling, and storing practices and willingness-to-buy attitudes of consumers.

\section{MATERIALS AND METHODS}

\section{Lettuce and Treatments}

Iceberg lettuce heads were purchased from a local grocery store in Griffin, $\mathrm{Ga}$. The store wrapping and two outermost leaves were removed. In Experiment 1 , control heads were rinsed under cool tap water for $1 \mathrm{~min}$ and then drained for $30 \mathrm{~min}$ in a lab cart basket lined with four layers of paper towels. After blotting dry, each head was cored and placed core-end down in a plastic container lined with four folded paper towels. Containers were sealed and stored at $5 \mathrm{C}$ for 0,6 , and 10 days.

For heads to be treated with antibacterial solution (Experiment 1), rinsed heads were held in a lab cart basket lined with four layers of paper towels until treated. Each head was cored, immersed individually (core-end up) for $5 \mathrm{~min}$ in $3 \mathrm{~L}$ of a $1.5 \%$ lactic acid plus $2.0 \%$ hydrogen peroxide solution at room temperature $(\sim 22 \mathrm{C})$. Plastic containers used for immersion were $4.1 \mathrm{~L}$ capacity with lid (Rubbermaid Servin' Saver, Rubbermaid Home Products Division, Wooster, $\mathrm{OH}$ ). Heads were kept submerged (core-end up) by placing the lid on the container; containers were agitated briefly halfway through the 5-min treatment. Immediately following treatment, heads were rinsed by immersing in running tap water for $5 \mathrm{~min}$; heads were rotated continuously during rinsing. Heads were then drained for $30 \mathrm{~min}$ in a lab cart basket lined with four layers of paper towels. After blotting dry, each head was placed core-end down in a plastic container lined with four folded paper towels. Containers were sealed and stored at $5 \mathrm{C}$ for 0,6 , and 10 days.

For heads to be neutralized (Experiment 2), rinsed heads were also held in a lab cart basket lined with four layers of paper towels until treated. Each head 
was cored, immersed (core-end up) individually for $5 \mathrm{~min}$ in $3 \mathrm{~L}$ of a $1.5 \%$ lactic acid plus $2.0 \%$ hydrogen peroxide solution at room temperature $(-22 \mathrm{C})$, then immediately immersed for $5 \mathrm{~min}$ in $3 \mathrm{~L}$ of a $2.5 \%$ sodium bicarbonate solution at room temperature $(\sim 22 \mathrm{C})$, followed by a final rinse (immersion in running tap water for $10 \mathrm{~min}$ ). The immersion, rinsing, draining, and storage procedures for the treated/neutralized heads were the same as those described for the treated samples in Experiment 1. In Experiment 2, control heads were rinsed for the same amount of time $(10 \mathrm{~min})$ as the treated/neutralized sample.

\section{Panelists}

A panel of 80 consumers from the local community was recruited by telephone from a database maintained at the Department of Food Science and Technology - Griffin Campus. Criteria for participation were that consumers (1) be at least 18 years of age, (2) be the primary shopper for the household, (3) purchase and eat iceberg lettuce, and (4) not be allergic to lettuce or the solutions used to wash the lettuce. Potential participants were told that the solutions were lactic acid (a common antimicrobial and pickling agent), hydrogen peroxide (an agent used in mouthwash and toothpaste), and sodium bicarbonate (baking soda), all of which were used in low concentrations and approved for food use by the U.S. Food and Drug Administration.

\section{Test Procedure}

In Experiment 1, five sensory evaluation sessions with eight panelists per session were conducted on two days (Jan. 20 - processing rep 1, Feb. 3 processing rep 2) to evaluate untreated (control) and treated lettuce stored for 0,6 and 10 days. Sessions were scheduled at 1-h intervals between 2:00 p.m. and 6:30 p.m. When consumers arrived, they were asked to fill out two consent forms approved by the University of Georgia Institutional Review Board, an honorarium form, and a demographic questionnaire. During orientation, panelists were instructed on the evaluation procedures and use of the signal lights in the sensory booths. Panelists were seated in individual partitioned booths in the climate-controlled sensory evaluation laboratory. Each booth was illuminated with incandescent lighting (473 lux).

For Experiment 2, the same test procedure was repeated on July 20 (processing rep 1) and July 27, 2000 (processing rep 2) when untreated (control) and treated/neutralized lettuce stored for 0,6 and 10 days were compared. During the 5-month period between the two sensory tests, microbiological studies (to be reported elsewhere) and storage trials were conducted to ensure the efficacy and safety of the treatment plus neutralization steps in inactivating E. coli, S. enteritidis, and L. monocytogenes. 
On the day of the test, each head was rinsed (core-end down) under cool tap water for $1 \mathrm{~min}$, drained over the sink for $10 \mathrm{~s}$, and then drained for $30 \mathrm{~min}$ in a lab cart basket lined with four layers of paper towels. For each sample, three heads were quartered and then coarsely chopped ( $30 \mathrm{~s}$ ) in a food cutter (model 84142, Hobart Manufacturing Co., Troy, $\mathrm{OH}$ ), mixed thoroughly, filled into 96 $\mathrm{mL}$ (3.25 oz) plastic portion cups labeled with 3-digit code numbers, covered with snap-on lids, and refrigerated until served later the same day. Samples were presented monadically (one at a time) in a random sequence. Panelists evaluated appearance and color first, then aroma, flavor, texture, and overall liking using a 9-point hedonic scale, with 1 = dislike extremely, $5=$ neither like nor dislike, and $9=$ like extremely. They also indicated whether the sample was acceptable (yes or no response). Water and unsalted crackers were provided for cleansing the palate between samples. Covered expectoration cups were provided if the panelists did not wish to swallow the samples.

After completing the sensory evaluation of chopped samples, panelists went into the preparation kitchen where both halves of one head from each of six samples were displayed, one side up and one side down, on white plates. Panelists evaluated the samples visually for appearance, color, and overall visual quality by rating them as either very good, acceptable, or unacceptable. They also indicated whether they would eat the sample (yes, maybe, or no).

After the visual quality evaluation, panelists completed a questionnaire, which dealt with lettuce purchasing, handling, and storing practices and willingness-to-buy attitudes. Panelists received a $\$ 10$ honorarium for their participation.

\section{Instrumental Color Measurements}

The color of chopped lettuce was measured using a Gardner colorimeter (model XL-845, Pacific Scientific, Bethesda, MD) standardized against a green reference tile $\left(L^{*}=70.38, a^{*}=-18.45, b^{*}=9.54\right)$. Sufficient sample was placed in a black sample cup ( $91 \mathrm{~mm}$ diameter) to completely cover the bottom. The lid was placed on the cup, and Hunter color readings $\left(L^{*}, a^{*}, b^{*}\right)$ were recorded. Four readings per sample were obtained by rotating the cup at $90^{\circ}$ angles. Psychometric color terms of chroma (intensity or saturation), hue angle, and total color difference $(\Delta \mathrm{E})$ were calculated from values of $\mathrm{L}^{*}$ (lightness), $+a^{*}$ (redness), $-a^{*}$ (greenness), $+b^{*}$ (yellowness), and $-b^{*}$ (blueness).

\section{Statistical Analysis}

Sensory ratings and instrumental color data were analyzed using the General Linear Model (GLM) procedure and one-way analysis of variance. For each experiment, data from the two processing reps were analyzed separately and then pooled since no difference was found between processing reps. Means and 
frequencies were obtained using the Statistical Analysis System (SAS Institute, Cary, NC). Significant means were separated using the Least Significant Difference (LSD) test $(P \leq 0.05)$.

\section{RESULTS AND DISCUSSION}

\section{Demographic Characteristics}

Participants ranged in age from 18 to 74 with $61 \%$ being 25 - 54 years old; $79 \%$ were females, and $72 \%$ were married. Consumers consisted of Caucasians (78\%), African-Americans (17\%), and Spanish/Hispanic/Asian (5\%). About $32 \%$ had completed high school, $27 \%$ had completed vocational school or some college, and $25 \%$ were college graduates. About $41 \%$ were employed full-time, $13 \%$ were part-time employees, $21 \%$ were unemployed, and $25 \%$ were retired. The median household income before taxes was $\$ 30,000$ to $\$ 39,000$.

\section{Lettuce Treated with Antibacterial Solution}

Sensory Quality. Mean ratings for sensory quality and acceptability of treated and control lettuce stored for 0,6 and 10 days at 5C are shown in Table 1. The controls stored for either 6 or 10 days received the highest hedonic ratings for all sensory attributes (5.9-7.0); ratings were in the "like slightly" to "like moderately" range and were significantly $(P \leq 0.05)$ different from the 0 -day control and treated lettuce. When participants were asked if the products were acceptable (yes $=1$, no $=2$ ), most consumers $(87 \%)$ considered control stored lettuce to be acceptable (1.12 and 1.14 , respectively). Treated lettuce at day 0 received intermediate hedonic ratings $(4.6$ to 5.3 ) for all sensory attributes ("dislike slightly" to "neither like nor dislike" range) and were significantly $(P$ $\leq 0.05$ ) lower compared with 0-day control lettuce (5.2-6.1). Treated lettuce stored for 0 days was considered marginally acceptable (1.56). Treated lettuce stored for 6 or 10 days received the lowest hedonic ratings $(3=$ "dislike moderately" to $4=$ "dislike slightly") for most sensory attributes and were considered the least acceptable ( 1.76 and 1.77 , respectively). The antibacterial solution treatment adversely affected the sensory quality of the lettuce, and sensory ratings decreased during storage.

Visual Quality. Results of visual evaluation of treated and control lettuce stored for 0,6 and 10 days at $5 \mathrm{C}$ are shown in Table 2. Ratings were $1=$ very good, $2=$ acceptable, and $3=$ unacceptable. At day 0 , the visual sensory quality of lettuce treated with antibacterial solution was similar to the controls. Treated lettuce at day 0 was rated as either very good or acceptable in appearance, color, and overall quality (1.52-1.58), whereas the control at day 0 was rated 1.64-1.68; the control stored for 10 days was rated 1.61-1.65. The 


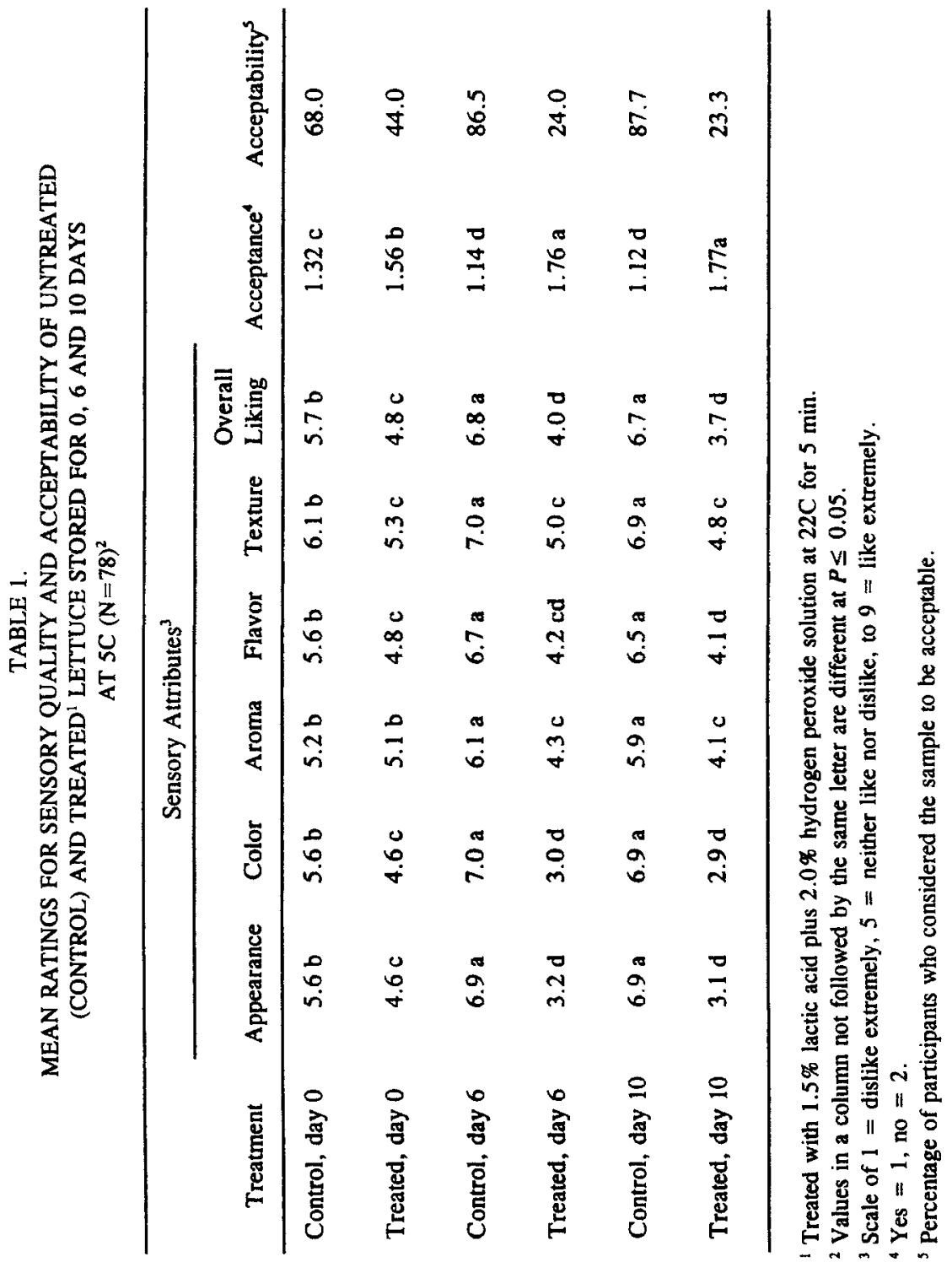


TABLE 2.

VISUAL QUALITY AND EATABILITY OF UNTREATED (CONTROL) AND TREATED ${ }^{1}$ LETTUCE STORED FOR 0, 6 AND 10 DAYS AT $5 C(\mathrm{~N}=78)^{2}$

\begin{tabular}{lcccccc}
\hline & \multicolumn{5}{c}{ Visual Attributes $^{3}$} & \\
\cline { 2 - 4 } Treatment & Appearance & Color & Overall & Would you eat? & Eatability \\
\hline Control, day 0 & $1.67 \mathrm{c}$ & $1.64 \mathrm{c}$ & $1.68 \mathrm{c}$ & $1.17 \mathrm{~cd}$ & 83.3 \\
Treated, day 0 & $1.52 \mathrm{c}$ & $1.52 \mathrm{c}$ & $1.58 \mathrm{c}$ & $1.16 \mathrm{~d}$ & 85.7 \\
Control, day 6 & $1.95 \mathrm{~b}$ & $1.87 \mathrm{~b}$ & $1.96 \mathrm{~b}$ & $1.32 \mathrm{bc}$ & 68.8 \\
Treated, day 6 & $2.92 \mathrm{a}$ & $2.89 \mathrm{a}$ & $2.88 \mathrm{a}$ & $2.43 \mathrm{a}$ & 3.9 \\
Control, day 10 & $1.65 \mathrm{c}$ & $1.61 \mathrm{c}$ & $1.65 \mathrm{c}$ & $1.36 \mathrm{~b}$ & 70.1 \\
Treated, day 10 & $2.97 \mathrm{a}$ & $2.91 \mathrm{a}$ & $2.96 \mathrm{a}$ & $2.49 \mathrm{a}$ & 1.3 \\
\hline
\end{tabular}

${ }^{1}$ Treated with $1.5 \%$ lactic acid plus $2.0 \%$ hydrogen peroxide solution at $22 \mathrm{C}$ for $5 \mathrm{~min}$.

${ }^{2}$ Values in a column not followed by the same letter are different at $P \leq 0.05$.

${ }^{3}$ Scale of $1=$ very good, $2=$ acceptable, and $3=$ unacceptable.

${ }^{4}$ Yes $=1$, maybe $=2$, and no $=3$.

${ }^{s}$ Percentage of participants who rated the sample to be eatable (Yes).

control stored for 6 days had significantly $(P \leq 0.05)$ higher ratings (1.87-1.96) compared with the control or treated lettuce at day 0 or control at day 10 . Visual quality declined markedly for treated lettuce stored for either 6 or 10 days. Stored treated lettuce had the highest ratings (i.e., poorest quality) for appearance, color, and overall quality (2.88-2.97). Panelists considered these samples to have unacceptable visual quality when evaluated in whole rather than chopped form. Primary reasons given by panelists for these samples being unacceptable were "looks bad" for appearance, "off color" for color, and "poor overall appearance" for overall.

Consumers were asked if they would eat the lettuce; lettuce treated at day 0 received the highest positive (yes) responses $(85.7 \%$ ), followed by control at day $0(83.3 \%)$, control at day $10(70.1 \%)$, and control at day $6(68.8 \%)$. About half of the respondents may have been willing to eat the treated samples at day 6 and day $10(48.7 \%)$. Samples which received the most no responses were those that had been treated and stored for 6 days $(47.4 \%)$ or 10 days $(50 \%)$. The primary reason was "poor appearance" and secondarily, "poor color" of these samples. 
Instrumental Color Measurements. Mean values for instrumental color measurements of treated and control lettuce stored for 0,6 and 10 days at $5 \mathrm{C}$ are shown in Table 3. The color of treated lettuce at day 0 was more saturated/intense (higher chroma value) and more yellow (higher $b^{*}$ ) than control at day 0 or treated lettuce stored for 6 and 10 days. Treated lettuce stored for 6 and 10 days was significantly $(P \leq 0.05)$ darker (lowest $L^{*}$ values) than the control stored for 0 and 10 days and treated lettuce at day 0 . Treated lettuce stored for 6 days was less green (lowest -a* value) than all other samples. Hue angles of $90^{\circ}$ represent yellow, and $180^{\circ}$ represents green. All of the samples were yellow-green, with the lettuce treated and stored for 6 days being less green (lower hue angle) than all other samples. Treated samples stored for 6 or 10 days received the lowest sensory ratings for color $(3.0$ and $2.9=$ dislike moderately), which may have been due to their darker (lower $\mathrm{L}^{*}$ values) color.

\section{Lettuce Treated with Antibacterial and Neutralizing Solutions}

Sensory Quality. Mean ratings for sensory quality and acceptability of lettuce treated with antibacterial and neutralization solutions (neutralized) and control lettuce stored for 0,6 and 10 days at $5 \mathrm{C}$ are shown in Table 4 . Neutralized lettuce at day 0 received hedonic ratings of 6.3-7.2 for all sensory attributes ("like slightly" to "like moderately" range) and were similar to the control at day $0(6.6-7.5)$. Most consumers $(90 \%)$ considered the neutralized lettuce to be acceptable (1.10). The sensory ratings for the controls stored for either 6 or 10 days were 5.9-6.8 ("like slightly" range) and were significantly $(P \leq 0.05)$ different from control and neutralized lettuce at day 0 . Most consumers (82.9-84.3\%) considered control stored lettuce to be acceptable (1.16-1.17). Neutralized lettuce stored for 6 or 10 days received the lowest hedonic ratings (2.7-4.6 and 2.0-3.6 for day 6 and day 10, respectively) for all sensory attributes and were considered the least acceptable (1.82 and 1.88 , respectively). Lettuce sensory quality was retained initially when treated with antibacterial and neutralizing solutions. However, sensory quality of both control and neutralized lettuce decreased with storage time.

Visual Quality. Results of visual evaluation of lettuce treated with antibacterial and neutralized solutions (neutralized) and controls stored for 0,6 and 10 days at $5 \mathrm{C}$ are shown in Table 5. Ratings were $1=$ very good, $2=$ acceptable, and $3=$ unacceptable. The visual sensory quality of neutralized lettuce was significantly $(P \leq 0.05)$ higher than the control. The control at day 0 was rated as either very good or acceptable in appearance, color, and overall quality (1.08-1.11) while the neutralized lettuce at day 0 was rated 1.39-1.44. Visual ratings increased significantly $(P \leq 0.05)$ with storage time. Ratings 


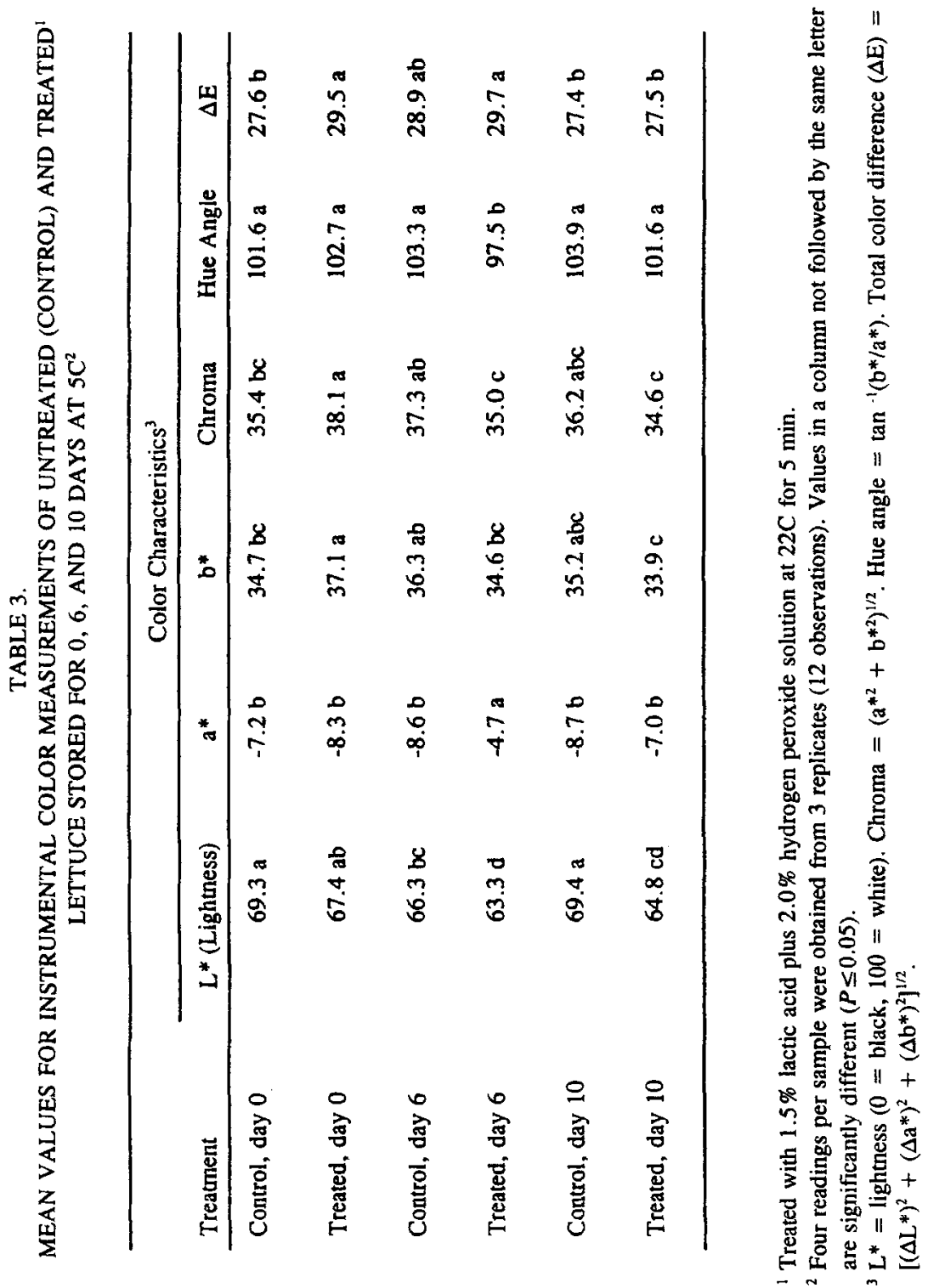




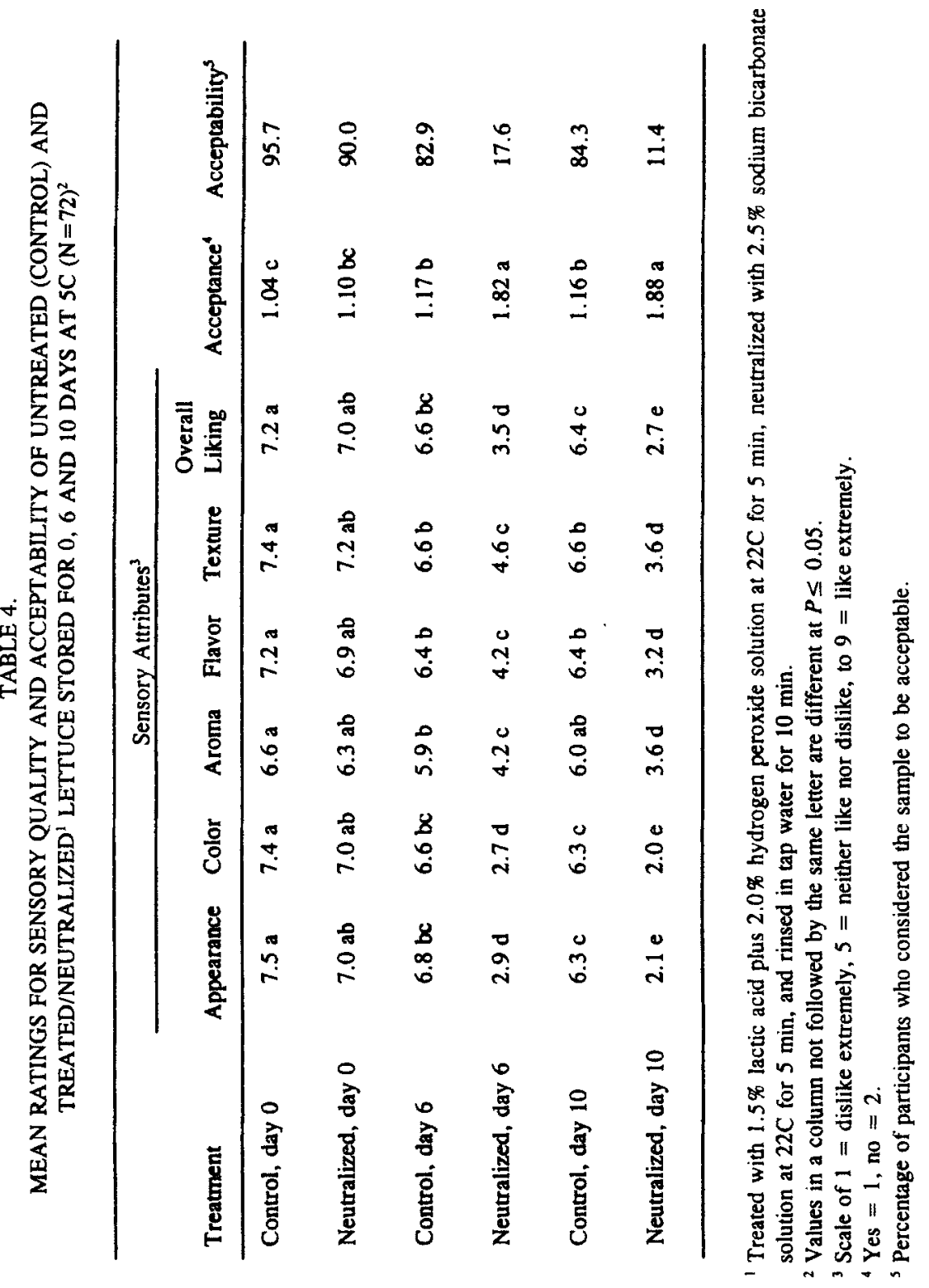


TABLE 5.

VISUAL QUALITY AND EATABILITY OF UNTREATED (CONTROL) AND

TREATED/NEUTRALIZED' ${ }^{\prime}$ LETTUCE STORED FOR

0,6 AND 10 DAYS AT $5 \mathrm{C}(\mathrm{N}=72)^{2}$

\begin{tabular}{|c|c|c|c|c|c|}
\hline \multirow[b]{2}{*}{ Treatment } & \multicolumn{3}{|c|}{ Visual Attributes ${ }^{3}$} & \multirow[b]{2}{*}{ Would you eat? ${ }^{4}$} & \multirow[b]{2}{*}{ Eatability } \\
\hline & Appearance & Color & Overall & & \\
\hline Control, day 0 & $1.08 \mathrm{f}$ & $1.10 \mathrm{f}$ & $1.11 \mathrm{f}$ & $1.03 \mathrm{e}$ & 97.2 \\
\hline Neutralized, day 0 & $1.41 \mathrm{e}$ & $1.39 \mathrm{e}$ & $1.44 \mathrm{e}$ & $1.24 \mathrm{~d}$ & 80.3 \\
\hline Control, day 6 & $1.62 \mathrm{~d}$ & $1.62 \mathrm{~d}$ & $1.63 \mathrm{~d}$ & $1.34 \mathrm{~d}$ & 71.8 \\
\hline Neutralized, day 6 & $2.38 \mathrm{~b}$ & $2.34 \mathrm{~b}$ & $2.42 \mathrm{~b}$ & $2.14 \mathrm{~b}$ & 32.4 \\
\hline Control, day 10 & $1.94 \mathrm{c}$ & $1.87 \mathrm{c}$ & $1.96 \mathrm{c}$ & $1.58 \mathrm{c}$ & 59.2 \\
\hline Neutralized, day 10 & $2.96 \mathrm{a}$ & $2.90 \mathrm{a}$ & $2.92 \mathrm{a}$ & $2.90 \mathrm{a}$ & 1.4 \\
\hline
\end{tabular}

${ }^{1}$ Treated with $1.5 \%$ lactic acid plus $2.0 \%$ hydrogen peroxide solution at $22 \mathrm{C}$ for $5 \mathrm{~min}$, neutralized with $2.5 \%$ sodium bicarbonate solution at $22 \mathrm{C}$ for $5 \mathrm{~min}$, and rinsed in tap water for $10 \mathrm{~min}$.

${ }^{2}$ Values in a column not followed by the same letter are different at $P \leq 0.05$.

${ }^{3}$ Scale of 1 = very good, $2=$ acceptable, and $3=$ unacceptable.

${ }^{4}$ Yes $=1$, maybe $=2$, and no $=3$.

${ }^{5}$ Percentage of participants who rated the sample to be eatable (Yes).

were $1.62-1.63,1.87-1.96$, and 2.34-2.42 for control at day 6 , control at day 10 , and neutralized at day 6 , respectively. Neutralized lettuce at day 10 had the highest ratings (i.e., poorest quality) for appearance, color, and overall quality (2.90-2.96). Most consumers (93-95.8\%) considered these samples to have unacceptable visual quality.

Consumers were asked if they would eat the lettuce; control lettuce at day 0 received the highest positive (yes) responses $(97.2 \%)$, followed by neutralized at day $0(80.3 \%)$, control at day $6(71.8 \%)$, and control at day $10(59.2 \%)$. About half of the respondents may have been willing to eat the neutralized lettuce at day 6 while only $8 \%$ were willing to eat the neutralized lettuce at day 10. The sample which received the most no responses $(91.5 \%)$ was the neutralized lettuce stored for 10 days $(91.5 \%)$.

Instrumental Color Measurements. Mean values for instrumental color measurements of lettuce treated with antibacterial and neutralizing solutions (neutralized) and controls stored for 0, 6 and 10 days at 5C are shown in Table 
6. The color characteristics of neutralized lettuce at day 0 were similar to the control at day 0 . Controls at day 6 and day 10 had similar color except were less green (lower $-\mathrm{a}^{*}$ values) than control at day 0 . Neutralized lettuce stored for 10 days was significantly $(P \leq 0.05)$ darker (lower $L^{*}$ values) than neutralized at day 0 and controls at day 0 , day 6 , and day 10 . Neutralized lettuce stored for 6 and 10 days was less green (lowest $-a^{*}$ value) and had lower hue angles than all other samples. Lettuce treated, neutralized, and stored for 10 days was the most different in total color (highest $\Delta \mathrm{E}$ ), largely because of its darker color; this sample received the lowest sensory ratings for color and appearance (2.0 and 2.1 ), which may also have been due to its darker (lower $L^{*}$ value) color.

TABLE 6.

MEAN VALUES FOR INSTRUMENTAL COLOR MEASUREMENTS OF UNTREATED (CONTROL) AND TREATED/NEUTRALIZED ${ }^{1}$ LETTUCE STORED FOR 0,6 , AND 10 DAYS AT $5 C^{2}$

\begin{tabular}{lcccccc}
\hline & \multicolumn{5}{c}{ Color Characteristics } \\
\cline { 2 - 7 } Treatment & $\mathrm{L}^{*}$ & $\mathrm{a}^{*}$ & $\mathrm{~b}^{*}$ & Chroma & Hue Angle & $\Delta \mathrm{E}$ \\
\hline Control, day 0 & $63.0 \mathrm{ab}$ & $-15.3 \mathrm{c}$ & $37.0 \mathrm{a}$ & $40.0 \mathrm{a}$ & $112.5 \mathrm{a}$ & $27.9 \mathrm{bc}$ \\
Neutralized, day 0 & $61.7 \mathrm{~b}$ & $-14.8 \mathrm{c}$ & $36.9 \mathrm{a}$ & $39.7 \mathrm{a}$ & $111.8 \mathrm{a}$ & $28.1 \mathrm{bc}$ \\
Control, day 6 & $65.6 \mathrm{a}$ & $-12.1 \mathrm{~b}$ & $36.9 \mathrm{a}$ & $38.8 \mathrm{a}$ & $108.2 \mathrm{~b}$ & $27.6 \mathrm{bc}$ \\
Neutralized, day 6 & $61.3 \mathrm{~b}$ & $-7.9 \mathrm{a}$ & $36.7 \mathrm{a}$ & $37.6 \mathrm{a}$ & $102.0 \mathrm{c}$ & $30.0 \mathrm{~b}$ \\
Control, day 10 & $65.4 \mathrm{a}$ & $-12.1 \mathrm{~b}$ & $35.4 \mathrm{a}$ & $37.4 \mathrm{a}$ & $108.9 \mathrm{~b}$ & $26.3 \mathrm{c}$ \\
Neutralized, day 10 & $54.9 \mathrm{c}$ & $-7.9 \mathrm{a}$ & $37.0 \mathrm{a}$ & $37.9 \mathrm{a}$ & $101.9 \mathrm{c}$ & $33.1 \mathrm{a}$ \\
\hline
\end{tabular}

${ }^{1}$ Treated with $1.5 \%$ lactic acid plus $2.0 \%$ hydrogen peroxide solution at $22 \mathrm{C}$ for $5 \mathrm{~min}$, neutralized with $2.5 \%$ sodium bicarbonate solution at $22 \mathrm{C}$, and rinsed in tap water for $10 \mathrm{~min}$.

2 Four readings per sample were obtained from 3 replicates (12 observations). Values in a column not followed by the same letter are significantly different $(P \leq 0.05)$.

${ }^{3} \mathrm{~L}^{*}=$ lightness $(0=$ black, $100=$ white $)$. Chroma $=\left(\mathrm{a}^{* 2}+\mathrm{b}^{* 2}\right)^{1 / 2}$. Hue angle $=\tan ^{-1}\left(\mathrm{~b}^{*} / \mathrm{a}^{*}\right)$. Total color difference $(\Delta \mathrm{E})=\left[\left(\Delta \mathrm{L}^{*}\right)^{2}+\left(\Delta \mathrm{a}^{*}\right)^{2}+\left(\Delta \mathrm{b}^{*}\right)^{2}\right]^{1 / 2}$.

\section{Lettuce Purchasing, Handling and Storing Practices and Willingness-to-buy Attitudes}

Information obtained about consumers' lettuce purchasing, handling, and storing practices and willingness-to-buy attitudes is reported in Table 7. Iceberg was the variety purchased most often. About $68 \%$ of the consumers purchased lettuce as a whole head, and $54 \%$ purchased lettuce at least once a week. 
TABLE 7.

LETTUCE PURCHASING, HANDLING, STORING, AND WILLINGNESS-TO-BUY CHARACTERISTICS OF CONSUMERS WHO PARTICIPATED IN LETTUCE QUALITY EVALUATION $(\mathrm{N}=150)$

Questions

Percentage

1. How often do you buy lettuce? $(n=149)$

Less than once a week

Once a week

38.9

Twice a week

10.7

Three or more times a week

2. What variety of lettuce do you purchase most often? $(n=148)$

Iceberg

Romaine

Leaf (red or green)

Mixed

3. What form of lettuce do you purchase most often? $(n=149)$

Whole head

68.5

Precut/packaged

30.2

Both whole head and precut/packaged

4. How do you store lettuce at home?

a. Store unwashed whole head in the refrigerator in: $(n=76)$

Store wrap

46.0

Plastic wrap

21.1

Closed container

11.8

Resealable bag

21.1

b. Wash the whole head and store refrigerated in: $(n=56)$

Store wrap

10.7

Plastic wrap

14.3

Closed container

30.4

Resealable bag

44.6

c. Wash and core the whole head, store refrigerated in: $(n=44)$

Store wrap

Plastic wrap

Closed container

Resealable bag

d. Store unwashed leaves in the refrigerator in: $(n=24)$

Store wrap

Plastic wrap

Closed container

Resealable bag

e. Store washed leaves in the refrigerator in: $(n=26)$

Store wrap

Plastic wrap

15.4

Closed container

30.8

Resealable bag 
TABLE 7. (CONTINUED)

f. Store unwashed precut/packaged lettuce in the refrigerator in: $(n=41)$

Store packaging

Closed container

Resealable bag

g. Store washed precut/packaged lettuce in the refrigerator in: $(n=42)$

Store packaging

Closed container

Resealable bag

5. Do you wash letuce purchased in the grocery store before consumption? (If no, go to question \#9) $(n=150)$

Yes

No

6. Do you drain washed lettuce before storage? (based on participants who responded yes to question $\# 5, n=130$ ) Yes

No

7. If yes, for how long? $(n=97)$

5 min or less

44.3

$15 \mathrm{~min}$ or less

14.4

$30 \mathrm{~min}$

9.3

One hour or more

3.1

Until dry or no drip

7.2

Spin dry or shake dry

9.3

Towel dry

8. How do you wash lettuce? (check all that apply)

Cool tap water $(n=118)$

Warm tap water $(n=6)$

Hot tap water $(n=1)$

Whole head $(n=48)$

33.8

Leaf by leaf $(n=37)$

Cored $(n=32)$

Uncored $(n=14)$

Remove outer leaves $(n=53)$

Use some type of vegetable wash $(n=2)$

9. Where do you store lettuce in your refrigerator? $(n=149)$

Vegetable drawer 
TABLE 7. (CONTINUED)

Questions

Percentage

10. Where do you store lettuce after you use it the first time? $(n=149)$

Vegetable drawer

79.9

In refrigerator body

20.1

11. How do you store lettuce after you use it the first time? $(n=148)$

Resealable bag

Closed container

Plastic wrap

Store wrap

14.9

12. How often do you eat lettuce? $(n=149)$

More than once a day

Once a day

5-6 times a week

6.0

3-4 times a week

33.6

1-2 times a week

27.5

less than once a week

21.5

13. How long do you store lettuce in the refrigerator? $(n=150)$

Less than 2 days

$2-4$ days

28.7

5-7 days

40.0

7-10 days

25.3

more than 10 days

2.0

14. In general, does the lettuce you keep at home stay fresh until you eat it? $(n=150)$

Yes

No

15. How do you decide if stored lettuce is no longer edible? (check all that apply)

Appearance (defects, color, etc.) $(n=143)$

Texture (wilting) $(n=91)$

60.7

Length of storage $(n=39)$

26.0

Odor $(n=71)$

47.3

Use by date, looks and taste $(n=2)$

16. When you eat lettuce, what is important to you? (check all that apply)

Flavor $(n=118)$

Aroma $(n=41)$

Crispness (texture) $(n=130)$

86.7

Appearance $(n=138)$

92.0

No preservatives, green color $(n=6)$ 
TABLE 7. (CONTINUED)

Questions

Percentage

17. Many outbreaks of foodborne illness caused by harmful microorganisms have been associated with eating fresh lettuce. $(n=149)$

True

19.4

False

Don't know

18. Have you been sick during the last 12 months from eating lettuce purchased from the grocery store? $(n=150)$

Yes

No

Don't know

19. Are you concerned about the possibility of becoming sick from eating lettuce? $(n=148)$

Yes

No

20. Would you be willing to buy an antibacterial solution (to kill harmful bacteria) for use in the home to treat lettuce prior to storage and/or consumption?

(If no, go to question $\# 26, n=150$ )

Yes

No

Undecided

21. If an antibacterial solution were available for home use, would you buy more, less, or about the same quantity of lettuce as you presently buy? $(n=107)$

More

Less

Same

22. If you choose to use an antibacterial solution to treat lettuce at home to be assured of "safe" vegetables, would you prefer: $(n=114)$

A ready-to-mix concentrate (dilute at time of use)

A premixed solution (ready to use)

23. If the instructions required the lettuce to be soaked for $5 \mathrm{~min}$ in the antibacterial solution at room temperature, would you still be willing to use it? $(n=113)$

Yes

No

24. Would you expect lettuce treated with an antibacterial solution to stay fresh longer that nontreated lettuce? (If no, go to question $\# 26, n=113$ )

Yes

No 
25. How much longer would you expect lettuce treated with an antibacterial solution to stay fresh at refrigeration temperature? $(n=79)$

$\begin{array}{lr}\text { No longer } & 1.3 \\ 1-7 \text { days } & 54.4 \\ 8-14 \text { days } & 40.5 \\ 15-21 \text { days } & 3.8\end{array}$

26. Would you be willing to buy letuce already treated at the packinghouse/processing plant with an antibacterial solution rather than using an at-home treatment? $(n=150)$

Yes

No

27. How much more would you be willing to pay for pre-treated lettuce? (based on participants who responded yes to question $\# 26, n=96$ )

1-2 cents more per head

In response to question \#17 about associating fresh lettuce consumption with outbreaks of foodborne illness caused by harmful microorganisms, $65.8 \%$ of the consumers indicated they did not know. Nearly all (93.4\%) indicated they had not been sick during the last 12 months from eating lettuce purchased from the grocery store; $80 \%$ were not concerned about the possibility of becoming sick from eating lettuce.

About $31 \%$ of the respondents would be willing to buy an antibacterial solution for use in the home to treat lettuce prior to storage and/or consumption whereas $48.7 \%$ were undecided. Considering these two groups together (yes and undecided), $79.4 \%$ of the respondents may constitute a potential market for an at-home antibacterial treatment. Of the consumers who indicated possible interest (yes or undecided) in willingness to buy an antibacterial solution for home use, $90.7 \%$ would buy about the same quantity of lettuce as they presently bought. If they chose to use an antibacterial solution to treat lettuce at home to be assured of "safe" vegetables, $82.5 \%$ would prefer a ready-to-use, premixed solution while $17.5 \%$ would prefer a ready-to-mix concentrate for dilution at the time of use. If the instructions required the lettuce to be soaked for $5 \mathrm{~min}$ in the antibacterial solution at room temperature, $70.8 \%$ would still be willing to use 
it. About $72 \%$ of the respondents would expect lettuce treated with an antibacterial solution to stay fresh longer than nontreated lettuce. Of those who expected extended shelf-life of treated lettuce, $54.4 \%$ expected $1-7$ days and $40.5 \%$ expected 8 - 14 days.

As an altemative to an at-home treatment, $70 \%$ indicated they would be willing to buy lettuce already treated at the packinghouse or processing plant with an antibacterial solution rather than using an at-home treatment. Considering this willingness by consumers to buy pretreated lettuce as well as the "treatat-home" concept, the market potential for an antibacterial treatment for lettuce appears to be quite promising. Of those who would buy pretreated lettuce, most $(83.4 \%)$ would be willing to pay at least 3 to 5 cents more per head.

\section{CONCLUSIONS}

Treatment of lettuce with $1.5 \%$ lactic acid plus $2.0 \%$ hydrogen peroxide at 22C for $5 \mathrm{~min}$ resulted in marginally acceptable lettuce at day 0 and an unacceptable product after 6 and 10 days of refrigerated storage. Modifying the treatment by adding a neutralization step resulted in lettuce which had acceptable sensory and visual quality immediately after treatment (day 0 ) but became unacceptable after 6 and 10 days of refrigerated storage. Loss of sensory quality during subsequent storage indicated treated/neutralized lettuce should be used in less than 6 days. Consumers were receptive to the concept of an antibacterial treatment for lettuce for use either in the home or at packinghouses/processing plants. Those who favored buying pretreated lettuce would be willing to pay at least 3 to 5 cents more per head.

\section{ACKNOWLEDGMENTS}

The authors gratefully acknowledge the technical support of Sue Ellen McCullough, Larry Hitchcock, Bob Flewellen, and Richard Stinchcomb. This study was funded in part by the U.S. Food and Drug Administration, Grant No. FD-U-001631-01-1.

\section{REFERENCES}

ABDUL-RAOUF, U.M., BEUCHAT, L.R. and AMMAR, M.S. 1993. Survival and growth of Escherichia coli $0517: \mathrm{H} 7$ on salad vegetables. Appl. Environ. Microbiol. 59, 1999-2006. 
ACKERS, M. et al. 1996. An outbreak of Escherichia coli 0157:H7 infections associated with leaf lettuce consumption, Westem Montana. Abstracts of the $36^{\text {th }}$ Interscience Conference on Antimicrobial Agents and Chemotherapy, Sept. 15-18, p. 257, New Orleans, LA.

BEUCHAT, L.R., NAIL, B.V., ADLER, B.B. and CLAVERO, M.R.S. 1998. Efficacy of spray application of chlorinated water in killing pathogenic bacteria on raw apples, tomatoes, and lettuce. J. Food Prot. 61, 1305-1311. BOYETTE, M.D., RITCHIE, D.F., CARBALLO, S.J., BLANKENSHIP, S.M. and SANDERS, D.C. 1993. Chlorination and postharvest disease control. Hort. Technol. 3, 395-400.

Centers for Disease Control and Prevention. 1997. Outbreak of cyclosporiasisNorthern Virginia - Washington, D.C. - Baltimore, Maryland Metropolitan Area, 1997. Morbid. Mortal. Weekly Rep. 46, 689-691.

DAVIS, H. et al. 1988. A shigellosis outbreak traced to commercially distributed shredded lettuce. Am. J. Epidemiol. 128, 1312-1321.

DELAQUIS, P.J., STEWART, S., TOIVONEN, P.M.A. and MOYLS, A.L. 1999. Effect of warm, chlorinated water on the microbial flora of shredded iceberg lettuce. Food Res. Intern. 32, 7-14.

ERCOLANI, G.L. 1976. Bacteriological quality assessment of fresh marketed lettuce and fennel. Appl. Environ. Microbiol. 31, 847-852.

FROST J.A., MCEVOY, M.B., BENTLEY, C.A., ANDERSON, Y. and ROWE, B. 1995. An outbreak of Shigella sonnei infection associated with consumption of iceberg lettuce. Emerg. Infect. Dis. 1, 26-29.

IFPA. 1996. Food Safety Guidelines for the Fresh-cut Produce Industry, 3rd Ed., pp. 70, 74. International Fresh-cut Produce Association, Alexandria, VA.

KAPPERUD, G. et al. 1995. Outbreak of Shigella sonnei infection traced to imported iceberg lettuce. J. Clin. Microbiol. 33, 609-614.

MASON, M.H. et al. 1976. Travelers' diarrhea in Mexico. N. Eng. J. Med. 294, 1299-1305.

MERMIN, J., MEAD, P., GENSHEIMER, K. and GRIFFIN, P. 1996. Outbreak of $E$. coli 0157:H7 infections among Boy Scouts in Maine. Abstracts of the $36^{\text {th }}$ Interscience Conference on Antimicrobial Agents and Chemotherapy, Sept. 15-18, p. 257, New Orleans, LA.

ROSENBLUM, L.S., MIRKIN, I.R., ALLEN, D.T., SAFFORD, S. and HADLER, S.C. 1990. Am. J. Publ. Health 80, 1075-1079.

SAPERS, G.M. and SIMMONS, G.F. 1998. Hydrogen peroxide disinfection of minimally processed fruits and vegetables. Food Technol. 52(2), 48-52. 